\title{
Texto e género: modalidade ou modalização? ${ }^{1}$ \\ Matilde Gonçalves \\ FCT, CLUNL ${ }^{2}$
}

\begin{abstract}
:
In this work, we have firstly focused on the difference between modality and modalization from a conceptual point of view, and then, we have analysed the marks of modalization in three texts belonging to the same sphere of activity - tourism. Apparently, those marks ultimately depend on the genres to which the texts belong.
\end{abstract}

Palavra-chaves: texto, modalidade, modalização, géneros, textos digitais.

Key-words: text, modality, modalization, genres, digital text.

\section{Introdução}

Compreender de que forma e com que meios o locutor se posiciona face ao que diz (dictum) e a quem o diz é um tema que suscitou, e suscita ainda, inúmeros debates em diversas áreas do conhecimento - linguística, lógica, filosofia e retórica, para citar algumas áreas. No presente artigo, proponho-me explorar outras vias da noção de modalização: mais do que descrever e analisar os valores modais, procurarei aferir as razões pelas quais determinado texto convoca determinada modalização em detrimento de outra. Para tal, serão analisados três textos digitais de língua portuguesa pertencendo ao mesmo domínio de atividade - o turismo - um sítio web (www.turismodeportugal.pt), um motor de busca (www.visitportugal.pt) e um blog (www.caboacabo.blogspot.pt). A escolha desta esfera de atividade prende-se com dois aspetos, a saber a relevância que o turismo, considerado um dos eixos de desenvolvimento do país através do Plano Estratégico Nacional do Turismo 2016-2020, adquiriu ao longo dos últimos anos, e o projeto de pós-doutoramento, que o presente artigo integra, no qual proponho analisar como se constrói o conhecimento de um ponto de vista linguístico-textual em sítios web do turismo português. Pela existência de duas vertentes observáveis a partir dos textos produzidos - uma responsável pelo planeamento e gestão e outra pela publicidade, o turismo representa um

\footnotetext{
${ }^{1}$ Agradeço à Helena Valentim, Antónia Coutinho e Audria Leal que enriqueceram o presente trabalho pelas trocas e discussões em torno da modalidade e modalização.

${ }^{2}$ Este artigo foi financiado pelos Fundos Nacionais da FCT - Fundação para a Ciência e Tecnologia, Projeto Estratégico UID/LIN/03213/2013 e bolsa de pós-doutoramento SFRH/BPD/66300/2009.
} 
interesse acrescido para a investigação que me proponho desenvolver: o estudo comparativo entre textos produzidos no seio das duas vertentes pretende analisar as diferenças linguísticodiscursivas mobilizadas, relacionando-as com diferentes objetivos e dando conta de diferentes posicionamentos, em termos de consciência prática e de consciência reflexiva, por parte dos agentes implicados (Giddens, 1987; Bronckart, 2004). Nesse sentido, o estudo da modalidade/modalização é um excelente ângulo de entrada para dar conta dos diversos posicionamentos dos agentes da esfera turística.

Importa também referir que a escolha do suporte digital surge na sequência do referido pós-doutoramento, mas também da necessidade de estudar géneros digitais, uma vez que escassos estudos sobre o contexto digital (Beaudouin, 2013, Gonçalves 2012, Marcuschi \& Xavier, 2005, Miller 2009, Trudel, 2013) evidenciam o interesse que estes objetos podem ter, nomeadamente as potencialidades de análise que contribuem a um melhor conhecimento da comunicação humana e da língua mobilizada pelos utilizadores e pelas instituições nos contextos digitais Por outro lado, a emergência do digital acresce um interessa a nível da investigação: a noção de género alterou-se com a emergência da internet? Quais as abordagens a serem adotadas face a objetos em permanente mudança? Como descrever os géneros digitais? Quais os critérios e instrumentos para descrever e analisar os géneros digitais? (Gonçalves, 2014).

Num primeiro tempo, realizar-se- á uma discussão em torno dos termos modalidade, modalização, em seguida, circunscrever-se-á a área do presente artigo - linguística do texto e do discurso, para finalmente, identificar as modalizações convocadas nos textos, na forma como são edificadas e seu papel na organização textual. Finalmente, será proposta uma objetivação da razão pela qual estes três textos convocam modalizações diferentes.

\section{Das diversas conceções da modalidade e da modalização}

É de opinião geral que a modalidade não é uma categoria consensual, quer pela heterogeneidade das unidades linguísticas tidas em conta para a análise, quer pela própria conceção de modalidade que pode ser estrita, intermédia ou lata, como sublinha N. Le Querler (1996), quer, ainda, pelas diferentes tipologias oriundas das classificações das diversas modalidades. Testemunho dessas ambivalências são também os termos que lhe estão associados, tais como modalidade, modalização, ou ainda valor modal. Se por modalidade se entende um conceito gramatical, que procura fundamentalmente descrever o posicionamento 
do locutor face ao que enuncia (Gramática da Língua Portuguesa, Mateus et alii., 2003, Gramática do Português, Raposo et alii., 2013), pode-se questionar a natureza e a aplicabilidade do termo, discussão ausente das gramáticas atrás referenciadas. Como suporte para a reflexão, vejamos alguns trabalhos que mencionam ambos os termos.

Valentim (2006) propõe uma reflexão rica sobre a modalidade, explorando as diversas abordagens sobre essa categoria. Na introdução do trabalho, a autora recorre aos termos "teorias lógicas da modalização" e "teorias linguísticas da modalização" para, referir, ao longo do artigo unicamente o termo modalidade. Num outro artigo, em 2008, sobre os modos gramaticais, Valentim, de acordo com Campos (1991), associa a modalização apreciativa à relação predicativa validada ou não validada construída na mesma situação de enunciação ( Sit $_{0}$ ) enquanto na modalidade apreciativa a relação predicativa é construída noutra situação de enunciação. É de sublinhar que esta conceção de modalidade não é estanque, sendo construída numa relação de dependência mútua com outras categorias gramaticais, nomeadamente a de tempo e aspeto (Campos \& Xavier, 1991: 339). No primeiro caso, contemplam-se exemplos tais como "felizmente, o Gil plantou uma árvore" e no segundo "é bom que o Gil esteja a plantar uma árvore".

No título do artigo "Modalidades linguísticas em textos processuais" (Pinto \& Bessa, 2010), é adotado o termo "modalidade", contudo, na página 298, encontra-se a opção das autoras de assumir o termo modalização em vez de modalidade pelo facto de este ser mais restrito $^{3}$. Se a questão da flutuação pode ser relacionada com a natureza heterogénea da modalidade, importa, fundamentalmente, determinar a razão de as linguistas optarem pela vertente mais ampla da modalização, quando trabalham no quadro do texto e/ou do discurso.

Já Duarte \& Pinto, num artigo de 2013 sobre a modalização linguística em artigos de opinião e cartoons da imprensa portuguesa, adotam assumidamente a escolha de "modalização", por esta, segundo as autoras, contemplar uma dimensão enunciativa, sem, no entanto, apresentarem uma distinção clara entre modalidade e modalização, como se pode verificar na seguinte citação:

\footnotetext{
${ }^{3}$ Para determinar a sua opção, as autoras recorrem à definição de Le Querler (1996: 63), segundo a qual a modalidade é a expressão da "atitude do locutor em relação ao conteúdo proposicional do seu enunciado".
} 
Assim, assumimos o conceito de modalização numa orientação predominantemente enunciativa, tomando como verdadeiro que a modalidade, numa tal conceção, engloba todas as manifestações da «subjetividade» no enunciado (Kerbrat-Orecchioni, 1980), pese embora o problema daí decorrente de que uma tal definição possa absorver todas as marcas diretas ou indiretas do sujeito no enunciado. (Duarte \& Pinto, 2013: 35)

Deste levantamento breve e não exaustivo, é de salientar dois aspetos relativos aos trabalhos que se situam numa ótica semântica (Costa \&Xavier, 1991 e Valentim, 2006, 2008): i) a necessidade de distinguir modalidade e modalização, ii) a interação entre modalidade e outras categorias gramaticais. Além disso, destacam-se dois outros aspetos que derivam das investigações enquadradas na linguística do texto e do discurso (Pinto \& Bessa ${ }^{4}$, Duarte \& Pinto): i) a dimensão da modalização como categoria mais ampla (relativamente a modalidade, tida como categoria mais restrita ${ }^{5}$ ), ii) a flutuação entre a escolha de um termo relativamente ao outro.

\section{Do texto}

O trabalho, que aqui se apresenta, assenta em dois autores, Eugenio Coşeriu e Jean-Paul Bronckart, de extrema relevância no âmbito dos estudos sobre o texto, enquanto objeto linguístico. Do primeiro, importa sublinhar a sustentação para a existência de um nível linguístico textual (Coseriu, 2001) e do segundo, um enquadramento e uma metodologia sólida e sustentada que torna possível uma análise do texto enquanto objeto global (e não como parte isolada) (Bronckart, 1997, 2008). A seguir apresentam-se algumas linhas orientadoras dos trabalhos destes autores que, apesar de não trabalharem na mesma corrente de pensamento, apresentam aspetos congruentes.

\subsection{Eugenio Coşeriu e a linguística do texto}

Eugenio Coşeriu publicou em 1980 Textlinguistik, obra na qual são apresentadas as diferenças fundamentais que deve assumir a linguística do texto relativamente à linguística, sublinhando assim a sua autonomia, contudo, é simultaneamente apontada a ideia que o texto

\footnotetext{
${ }^{4}$ J. Bessa trabalha no quadro da TFE, mas no artigo, a modalização é encarada na linguística textual/genérica.

${ }^{5}$ Repare-se que Vion (2006) apresenta uma proposta contrária. De facto, propõe uma conceção mais restrita para a noção de modalização, à qual Monte (2011) adere.
} 
não é um nível isolado, mas sim um outro nível do linguístico. Assim, a linguística do texto é outra disciplina que se encaixa na "linguística integral". Partindo da definição geral da linguagem, enquanto atividade humana universal exercida individualmente e que segue regras e normas históricas (Coşeriu, 2007: 86), são estabelecidos três níveis do linguístico: o universal que diz respeito à fala e à linguagem em geral, o histórico que incide sobre as línguas históricas e o último, o dos textos que corresponde aos atos linguísticos escritos e orais individuais. A proposta de Coşeriu é formular, em consonância com os três níveis do linguístico, três níveis para a linguística: 1) linguística da fala em geral, 2) linguística das línguas, 3) linguística dos textos. O linguista fundamenta a existência da autonomia do nível do texto (e consequentemente da linguística textual) pela existência de uma "classe de conteúdo" coincidente com o conteúdo do texto ou dado através dos textos. (Coşeriu 2007: 156) Em suma, o texto, para Coşeriu, é um macrosigno produto de uma dupla relação semiótica, a "designação" e o "significado" formando em conjunto uma unidade de conteúdo superior e mais complexa, o sentido (Coşeriu, 2007: 63, 233 e seguintes).

\subsection{Bronckart e o interacionismo sociodiscursivo}

O interacionismo sociodiscursivo (ISD) (Bronckart, 1997, 2008), herdeiro dos trabalhos de Vygotsky e Voloshinov, procura demonstrar o papel central da língua em todos os aspetos do desenvolvimento humano. De facto, o ISD sustém que as práticas de linguagem situadas (textos e discursos) são os principais instrumentos do desenvolvimento e da integração do ser humano na sociedade. Assim, os textos são produções sociais, resultado da atividade humana, que implicam no seu funcionamento realizações linguísticas, que vão, em particular, depender do contexto de comunicação. Aquando da construção e organização textual, o agente produtor realiza duas escolhas primordiais - a primeira é o género textual que prescreverá a organização e a interpretação do texto e a segunda, as unidades linguísticas que serão semiotizadas no produto textual (Bronckart, 2008). A metodologia convocada neste quadro teórico é descendente, indo das atividades de linguagem, aos géneros e textos e, a partir de aí, às unidades linguísticas mobilizadas nos textos. Além disso, o ISD centra-se em duas noções essenciais, desenvolvidas nesse mesmo quadro - a ação de linguagem e o modelo da arquitetura textual. A primeira procura conceptualizar as condições concomitantes de produção dos textos, ao passo que a segunda corresponde à arquitetura textual, descrita como um folhado constituído por três níveis organizacionais que interagem entre eles. A infraestrutura coincide com o nível mais 
profundo da arquitetura e reúne o conteúdo temático e os tipos de discurso. A seguir a este, advém o nível intermédio, o dos mecanismos de textualização, em relação com a progressão do conteúdo temático do texto, englobam a conexão e a coesão nominal. O último nível que inclui os mecanismos enunciativos que dependem da situação de comunicação (daí a sua pertença a um nível superficial) e engloba a "responsabilidade enunciativa", a "distribuição das vozes" e as "atribuições modais". No presente artigo, centrar-me-ei neste último nível que, como foi referido, é o mais sensível à ação de linguagem, ou seja, aos parâmetros contextuais.

\subsection{As modalizações}

Partindo da multitude de classificações da modalidade desde a Antiguidade, Bronckart (2008:84) retém três classes de modalizações, redefinidas relativamente à teoria dos três mundos de Habermas (1984): a modalização lógica, a modalização deôntica e a modalização subjetiva.

Les modalisations ont pour finalité générale de traduire les divers commentaires ou évaluations qui sont formulés, depuis n'importe quelle voix énonciative, à propos de certains éléments du contenu thématique. (...) les modalisations sont, elles, relativement indépendantes de cette linéarité et de cette progression: les évaluations qu'elles traduisent sont à la fois locales et discrètes (par rapport au caractère isotopique des marques de textualisation) et elles sont susceptibles de s'insinuer à n'importe quel niveau de l'architecture textuelle.

Importa realçar que o autor assume ao longo dos seus trabalhos a opção do termo modalização relativamente a modalidade. A modalização lógica agrupa a modalização alética e epistémica, diz respeito ao mundo objetivo definido por Habermas e apresenta elementos semiotizados sob o ângulo da sua condição de verdade, ou seja, se o que é dito é apresentado como sendo atestado, certo, possível, provável, eventual ou necessário. No que concerne à modalização deôntica, esta está em relação estreita com o mundo social descrito por Habermas, dado que os factos reenviam ao direito, à obrigação social e/ou em conformidade com as normas de uso (Bronckart, 2008: 84). Relativamente à modalidade apreciativa ou avaliativa, relacionada com o mundo subjetivo, esta apresenta os factos relativamente à voz que é fonte de julgamento, como podendo ser benéfica, estranha, positiva, etc. 
Ao retomar a definição de modalização proposta por J. P. Bronckart no XXV Encontro Nacional da Associação Portuguesa de Linguística, que decorreu em 2009:

La modalisation sert à expliciter les jugements ou évaluations émanant de ces instances [voix énonciatives] et s'adressant à certains aspects du contenu sémiotisé dans le texte, ou à certains aspects du processus même de sémiotisation ; elle est réalisée par des unités ou ensembles d'unités linguistiques de niveaux très divers : temps du verbe au mode conditionnel, auxiliaires de modalisation, certains adverbes, certaines phrases impersonnelles (Bronckart, $2010: 30$ )

observa-se que a noção proposta pelo autor é mais ampla do que a categoria gramatical modalidade, uma vez que o que se pretende realizar é a descrição e compreensão dos diversos mecanismos de responsabilização enunciativa, como foi explicitado anteriormente no que concerne ao quadro teórico do ISD.

\section{Análise de três textos}

É de referir que os textos, objetos de análise no presente artigo, pertencem a um corpus mais vasto, escopo de um projeto de pós-doutoramento sobre a construção do conhecimento de um ponto de vista linguística em sítios web da esfera turística (SFRH/BPD/66300/2009), recolhidos entre julho de 2013 e janeiro de 2014 (as datas de consulta estão indicadas nas referências bibliográficas). Os textos escolhidos fazem parte da esfera digital, que interessa e motiva um número crescente de pesquisas, seja no domínio da comunicação ou da linguística textual e discursiva (Gonçalves, 2014). Marcuschi (2007) num estudo sobre os hipertextos, que pode ser aplicado aos textos digitais, enumera diversas características, entre as quais a plurisemiose, a não linearidade e a volubilidade. ${ }^{6}$ Tanto os sítios web, os portais, como os blogs são constituídos por uma vertente linguística e outra não linguística, na qual se encontram imagens, filmes, animações (flash), sons que estabelecem uma interação com a parte verbal por forma a atrair o utilizador/leitor do texto, mantê-lo naquele espaço para não clicar em outro link e sair da página e finalmente auxiliá-lo a construir um sentido, ou pelo menos a determinar o conteúdo temático. A não linearidade constitui o segundo traço escolhido e incide na grande

\footnotetext{
${ }^{6}$ Marcuschi retoma alguns traços característicos desenvolvidos por Bolter (1991) relativamente aos hipertextos.
} 
flexibilidade na organização dos textos (Gonçalves, 2011, 2013). De facto, a presença de links entre as diversas páginas digitais constitui redes; o leitor pode, assim, escolher o seu percurso de leitura. Finalmente, os textos digitais não possuem a mesma estabilidade que os textos que circulam em suporte papel. Assim, as escolhas do agente produtor do texto podem ser escolhas efémeras uma vez que os textos não são fixos. De facto, pelo suporte digital, os textos podem ser alterados e/ou atualizados, daí a necessidade de referir a data na qual o texto digital foi consultado.

\subsection{Sítio web do Turismo de Portugal}

A escolha da primeira página do sítio do Turismo de Portugal prende-se com o facto de ser o primeiro contacto entre o utilizador e a entidade, Turismo de Portugal, daí a importância de ser uma página atrativa com o intuito de prender e motivar o utilizador a prosseguir a sua leitura no seio do sítio. A página principal tem como característica a presença de inúmeros links definidos como conexão entre os diversos conteúdos disponíveis no seio do mesmo sítio web (links internos) e links externos. A presença dos links influencia a organização textual e a escolha das unidades linguísticas. De facto, observam-se construções semelhantes aos títulos: enunciados construídos com um grupo sujeito e ausência de verbos (ex. Linha de Crédito, PME Crescimento).

No que concerne às modalizações na primeira página do Turismo de Portugal, não se encontram marcadores modais. Deduz-se, perante essa ausência, a presença da modalização lógica pois, do meu ponto de vista e de acordo com Culioli (1990) e Charles Bally (1944), todo o enunciado constrói um valor modal, ou seja, há sempre modalização mesmo que não sendo marcada. Nesse sentido, considera-se que o conteúdo temático é dado pela modalidade lógica ou epistémica, uma vez que os factos e os dados são apresentados em função da condição de verdade; são expostos como sendo reais e necessários ao bom funcionamento do turismo português, dado que esta entidade é responsável pela organização, legislação e desenvolvimento deste domínio social:

(1) Declaração de Interesse para o Turismo eliminada pelo Regime Jurídico dos Empreendimentos Turísticos.

(2) VIII Congresso de Ornitologia da SPEA de 1 a 4 de março em Almada.

(3) Turismo de Portugal quer agilizar atribuição de vistos. 


\subsection{O portal - Visit Portugal}

O "portal” ou motor de busca é pouco ou quase não é considerado como objeto de estudo na linguística do texto e do discurso. Só se encontra referenciado, ao que me consta, em Marcushi \& Xavier 2005, mas não é retomado posteriormente por esses autores. Esta classe de texto tem como objetivo a recolha e disponibilização de informação relativamente a determinado tema. No que concerne ao portal "Visit Portugal", este prende-se com a "prestação de informações e a sugestão de itinerários para os utilizadores que pretendam conhecer e/ou visitar Portugal, como consta nos Termos e Condições do portal" (https://www.visitportugal.com/pt-pt/termos-e-condicoes, acedido a 13 de fevereiro de 2017). Da observação das marcas de modalização conclui-se a construção da modalização lógica:

(4) Aldeias históricas - Feitas de granito, guardam história de conquistas e tradições antigas

(5) Vale do Douto a dois - O vale do Douto, Património Mundial, é um lugar encantado para descobrir a dois

Um aspeto de grande interesse é a presença de inúmeras formas do imperativo, quer a nível da página inicial, como se pode observar a seguir: "Pesquise", "Siga-nos", "encontre", "Explore Portugal", "Selecione", "descubra". A maioria destas formas do imperativo correspondem a links, funcionam, deste modo, como apelo direto ao utilizador a realizar um clique. Assim, o recurso a estas formas verbais funciona como edificador da modalização deôntica, dado que integram o mundo social (Habermas) e pretendem intervir no comportamento do utilizador, isto é, pretendem instaurar uma obrigação (Campos, 1998).

Uma primeira constatação pode ser realizada: apesar de ser a mesma atividade turística e a mesma unidade- o link -, observa-se que a modalização construída é diferente e os recursos linguísticos também.

\subsection{Blog - Cabo a cabo}

Os blogs, relativamente aos sítios, são considerados como um género textual estabilizado, fruto de numerosos estudos (Leibrandt, 2006; Lenhart \& Fox, 2006; Marcushi \& Xavier, 2005, Seara, 2010, entre outros). Apresenta como característica notável o facto de se organizar em função de uma sequência anti-cronológica (do mais recente ao mais antigo). Neste 
texto, foram encontrados dois tipos de modalizações: a modalização lógica e a apreciativa. $\mathrm{Na}$ primeira parte, correspondendo sensivelmente ao primeiro parágrafo ${ }^{7}$, o produtor textual menciona a preparação da viagem. Neste bloco textual, predominam as marcas de modalização lógica "recordo a primeira vez que visitei Varsóvia". É de notar o recurso ao condicional:

(6) Começaríamos por Gdansk, descíamos a Varsóvia e seguidamente a Cracóvia, de onde visitaríamos Auschwitz e as minas de sal de Wieliczka.

Tal como descrito nas gramáticas, o condicional pode ser considerado como um modo (Mira Mateus et alii 2003: 256-257) ou como tendo um valor temporal "futuro do passado" (Paiva Raposo et alii 2013: 527). No caso em apreço, o recurso ao condicional não marca uma temporalidade orientada no passado, mas sim um valor contrafactual pelo facto de a situação descrita não se ter realizado como planeado (cf. exemplo 5). Assim, a modalização lógica adquire, através do recurso ao condicional, um valor de incerteza. Outro aspeto a destacar, ainda nesta parte, é a presença do adjetivo "agradável" formado por um sufixo derivacional que constrói um valor apreciativo por parte do produtor relativamente ao país que visitou; a modalização apreciativa pode ser construída a partir de formas lexicalizadas como é o caso deste adjetivo (cf. Campos, 2005).

Na segunda parte do texto, relativa ainda ao período anterior à viagem e à leitura de uma obra, encontram-se valores da modalização lógica:

(7) crescia em mim a vontade de vasculhar in loco, as memórias desse gueto.

No terceiro bloco, relativo à história de Varsóvia, é a modalização lógica que é construída tal como na parte precedente. Os factos são expostos sem que o produtor textual emita qualquer comentário ou avaliação:

(8) A criação do Gueto de Varsóvia remonta a 1940, altura em que a ocupação nazi fez circunscrever a um espaço de apenas $2,4 \%$ do território da cidade.

\footnotetext{
${ }^{7}$ Apesar de este aspeto não ser desenvolvido no presente artigo, deve-se referir que a constituição dos parágrafos no post "Memórias do gueto" apresenta problemas. De facto, num mesmo parágrafo surgem macroestruturas (van Dijk, 1980) diferenciadas.
} 
Na terceira parte, iniciada com o marcador temporal "hoje", a presença do advérbio "dificilmente" marca um valor apreciativo, pois, do produtor emana um juízo de valor. Esse juízo de valor é reforçado com termos tais como "horrores" e "ensombravam", que denotam uma avaliação negativa, como se pode conferir no exemplo 9:

(9) Hoje, ao caminharmos pelas estas ruas, dificilmente nos damos conta dos horrores que ensombravam a cidade por esses dias. Mas as lembranças estão lá. Não há como esquecer. Não se pode esquecer!. ${ }^{8}$

A utilização da negação e a pontuação (ponto de exclamação) em "não se pode esquecer!" reforçam a manifestação de um ponto de vista e funcionam, indubitavelmente, como marcas avaliativas por parte do produtor textual. O recurso ao verbo modal "poder" concretiza a construção da modalização deôntica, estabelecendo uma ligação com mundo social conceptualizado e descrito por Habermas. A quarta parte relata o passeio pelas ruas de Varsóvia e as lembranças pessoais associadas ao espaço. Predomina nesta parte a modalização lógica com a exposição dos eventos vividos como sendo atestados. Encontram-se pontualmente expressões que edificam as avaliações do produtor textual "há algo de estranho nestes sobreviventes mudos" ou ainda termos que emitem um juízo de valor "um olhar triste, profundo e amargurado", "Umschlagplatz já não é mais lugar de partidas infames".

Deter-me-ei na última parte do post:

(10) Varsóvia é uma sereia de muitos encantos. O bairro judaico pode não ser a mais bela das suas faces, mas é aqui - nas suas ruas, nos seus edifícios e monumentos - que vive uma das mais importantes páginas da sua história, e é nessas calçadas e pareces, que as lembranças dessa história se manifestam.

Neste trecho, o adjetivo "bela" pode levar a considerar a existência da modalização apreciativa, contudo o que aqui é construído é uma apreciação relativamente a uma entidade - a cidade de Varsóvia. O produtor, apesar de emitir um juízo de valor, realiza uma predicação sobre essa entidade, define uma propriedade sem construir um valor apreciativo, como se

\footnotetext{
${ }^{8}$ Nos exemplos citados transcreve-se o texto tal como consta no post. 
poderia encontrar em "felizmente/infelizmente, o bairro judaico ser/não ser a mais bela das suas faces..." Contudo, ao ter em conta o enunciado na íntegra e o recurso ao adversativo "mas" iniciando a subordinada "mas é aqui (...) que vive uma das mais importantes páginas da sua história, e é nessas calçadas e pareces, que as lembranças dessa história se manifestam", deparamo-nos com a manifestação inequívoca de uma apreciação por parte do produtor, em particular na secção "uma das mais importantes páginas da sua história". De facto, nesta passagem o produtor está a construir uma valoração positiva "a mais importante" sobre algo já predicado "Varsóvia tem páginas importantes da sua história". Como se viu, esta avaliação não pode ser considerada gramaticalmente como uma modalidade apreciativa, no entanto, dela emana um julgamento, uma avaliação.

\subsection{Discussão dos resultados}

Trabalhar com textos e discursos solicita necessariamente a utilização de instrumentos que deem conta das diversas unidades linguísticas - donde a perspetiva estritamente gramatical ser fundamental - contudo convoca também ferramentas que auxiliem na determinação de como o produtor se inscreve na e pela língua, como mobiliza os recursos linguísticos para manifestar o seu querer-dizer, construir conhecimento e integrar-se o meio social no qual convive, tendo em conta as influências externas do contexto sócio-histórico. Face ao exposto, a modalização, enquanto categoria mais lata, poderá ser uma via para determinar o posicionamento do produtor e sua subjetividade (Kerbrat-Orecchioni, 1980) face ao que produz linguisticamente. Todavia, trabalhar com categorias mais latas acarreta o risco de abranger ou ter de abranger todos os traços do produtor no texto, tal como frisam Duarte \& Pinto (2013:35).

Dos diferentes valores de modalização e como são construídos nos diversos textos analisados, conclui-se que: i) na página inicial do sítio web, encontram-se marcas de modalização epistémica nos links, ii) no portal, ressaltam marcas de modalização epistémica e deôntica, iii) no blog, destacam-se as modalizações epistémicas e apreciativas. Dois comentários procedem às análises: o primeiro relativo à assimetria no que concerne aos resultados entre os três textos. De facto, os recursos linguísticos mobilizados na construção dos diferentes tipos de modalização são mais ricos e mais numerosos no caso do blog. Este fenómeno pode derivar da procura de objetividade e distanciamento por parte da entidade Turismo de Portugal, que gere o sítio web e o portal, manifestando-se no texto, dependendo dos casos, quer pela ausência de marcas explícitas, quer por um número reduzido de marcas de 
modalização. $\mathrm{O}$ segundo comentário incide na razão pela qual três textos pertencendo à mesma esfera de atividade - o turismo - convocam modalizações distintas (tendo a modalização epistémica em comum) e diversas semiotizações. Uma resposta possível poderá ser a pertença dos três textos a três géneros textuais diferentes, com objetivos comunicativos particulares e, consequentemente, marcas linguísticas específicas. Muito brevemente, o Turismo de Portugal, pelo sítio, procura fundamentalmente construir uma imagem objetiva, neutra e profissional do turismo português, uma vez que esta entidade se propõe gerir e desenvolver este domínio de atividade. O portal de turismo VisitPortugal pretende disponibilizar informação útil para o futuro turista e incentivar este a descobrir ou conhecer melhor Portugal. Finalmente, Mateus Brandão, pelo seu blog, procura sobretudo partilhar as lembranças, sensações de uma viagem.

\section{Conclusões ainda por concluir}

Com a escolha deste título para a presente secção, pretendo sublinhar que o percurso realizado ao longo deste trabalho evidencia algumas pistas de reflexão que precisam ainda de ser desenvolvidas para alcançar conclusões quer mais gerais sobre as diferenças e semelhanças entre modalização e modalidade, quer sobre o contributo da modalização para a análise textual/discursiva, quer para uma possível transposição/adaptação de uma categoria gramatical mais estrita para uma categoria mais lata de âmbito enunciativo-textual. A par destas reflexões, é de salientar que este trabalho evidenciou três aspetos: a utilização do termo modalização ainda não está estabilizada, existe, portanto, uma flutuação entre o uso deste em vez de modalidade (quando se pretende efetuar uma diferenciação); a categoria gramatical modalidade não é suficiente para dar conta da complexidade das configurações usadas pelo produtor textual para construir as suas avaliações; e finalmente, a questão do género textual é uma pista influente a considerar na apreensão da modalização.

\section{Referências}

Bally, Charles (1944 [1932]) Linguistique générale et linguistique française. Berne, Éditions Francke.

Bolter, Jay David (2001) Writing space: computers, hypertext and the remediation of print. Mahwah, New Jersey: Lawrence Erlbaum. 
Bronckart, Jean-Paul (1997) Activité langagière, textes et discours. Pour un interactionnisme discursif. Lausanne : Delachaux et Niestlé.

Bronckart, Jean-Paul (2010) La vie des signes en questions: des textes aux langues, et retour. In Textos Seleccionados, XXV Encontro Nacional da Associação Portuguesa de Linguística, Porto, APL, 2010, pp. 11-40.

Bronckart, Jean-Paul (2008) Genre de textes, types de discours et "degrés" de langue. In Texto! Janvier, vol. XIII, http://www.revue-texto.net/index.php?id=86 (consultado a 15 de janeiro de 2014).

Campos, Maria Henriqueta Costa \& Maria Francisca Xavier (1991) Sintaxe e Semântica do Português. Lisboa: Universidade Aberta.

Campos, Maria Henriqueta Costa (1998) Dever e Poder - um Subsistema Modal do Português. Lisboa: Fundação Calouste Gulbenkian.

Campos, Maria Henriqueta Costa (2005) A modalidade apreciativa: uma questão teórica. In F. Oliveira \& I. M. Duarte (orgs), Língua e Discurso - Homenagem a Joaquim Fonseca. Porto: Campo das Letras.

Duarte, Isabel Margarida \& Alexandra Guedes Pinto (2013) Troika, austeridade, crise: modalização linguística em artigos de opinião e cartoons na imprensa escrita portuguesa. Redis: revista de estudos do discurso, $\mathrm{n}^{\circ} 2$, pp.33-52.

Gonçalves, Matilde (2011) Espécie de texto: contributo para a caraterização do sítio web. In Hipertextus $\mathrm{n}^{\circ} 7$. Revista digital, ISSBN 1981-6081 [Latindex].

Gonçalves, Matilde (2013) "Organização textual e (des)linearidade: o caso dos sítios web" Estudos Linguísticos/Linguistics Studies 8, Lisboa, Colibri, pp.133-147.

Gonçalves, Matilde (2014) Similitudes et différences textuelles dans les genres numériques : blog et site web. Studii de lingvistică 4, 2014, 75 - 91. In http://studiidelingvistica.uoradea.ro/docs/4-

2014/articole\%20pdf\%20SL4/Goncalves.pdf .

Leibrandt, Isabella (2006) El weblog, un nuevo género de la cultura popular digital. In Culturas Populares. Revista Electrónica 3 (septiembre-deciembre 2006) http://www.culturaspopulares.org/textos3/articulos/cortes.pdf (consultado a 15 de janeiro 2014). 
Lenhart, Amanda \& Susannah Fox (2006) Bloggers. A portrait of the internet's new storytellers, http://www.pewinternet.org/pdfs/PIP\%20Bloggers\%20Report\%20July\%2019 \%202006.pdf (consultado a 15 de janeiro 2014).

Le Querler, Nicole (1996) Typologie des Modalités. Caen : Presses Universitaires de Caen.

Marcuschi, Luiz Antonio \& A. Carlos Xavier (éd.) (2005) Hipertexto e gêneros digitais. Novas formas de construção de sentido. Rio de Janeiro: Lucerna.

Marcuschi, Luiz António (2007) Cognição, linguagem e práticas internacionais. Rio de Janeiro: Lucerna.

Monte, Michèle (2011) Modalités et modalisation: peut-on sortir des embarras typologiques?, Modèles linguistiques [En ligne], 64/2011, mis en ligne le 05 septembre 2013, consulté le 31 mai 2017. URL: http://ml.revues.org/353; DOI : $10.4000 / \mathrm{ml} .353$.

Pinto, Rosalice, Bessa Janete (2010) Modalidades linguísticas em textos processuais. In Estudos Linguísticos/Linguistic Studies, 5, Edições Colibri/CLUNL: Lisboa, 2010, pp. 293-306.

Seara, Isabel (2010) Le blog: Frontières d'un nouveau genre. In Actes du XXVe Congrès International de Linguistique et Philologie Romanes (Innsbruck, 3-8 septembre 2007). Tübingen: Niemeyer, pp. 243-252.

Valentim, Helena Topa (2006) Elementos para uma epistemologia da modalidade. In XXI Encontro Nacional da Associação Portuguesa de Linguística, Lisboa: APL, pp.23-32.

Valentim, Helena Topa (2008) Modos gramaticais e modalidades - algumas particularidades do Português Europeu. In Kalewska, A. (ed.) Diálogos com a Lusofonia. Actas do Colóquio comemorativo dos 30 anos da Secção Portuguesa do Instituto de Estudos Ibéricos e Ibero-americanos da Universidade de Varsóvia. Warsaw: Instytut Studiów Iberyjskich i Iberoamerykańskich UW Warszawa, pp. 421-438 (http://iberystykauw.home.pl/pdf/Dialogos-Lusofonia/Coloquio_ISIiIUW_32_VALENTIM-

Helena_Modos-gramaticais-e-modalidades.pdf (consultado em 13 de novembro de 2017).

Vion, Robert (2004) Modalités, modalisations et discours représentés, Langages, 38e an., $\mathrm{n}^{\circ} 156,2004$. pp. 96-110. 
Vion, Robert (2005) Modalisation, dialogisme et polyphonie. In Laurent Perrin (éd.), Le sens et ses voix. Dialogisme et polyphonie en langue et en discours, Metz, Publications de l’Université de Metz, coll. " Recherches linguistiques ", pp. 105-125.

Vion, Robert (2006) Reprise et modes d'implication énonciative. La linguistique, vol. 42, (2), pp.11-28. doi:10.3917/ling.422.0011.

Van Dijk, Teun. A. (1980) Macrostructures - An Interdisciplinary Study of Global Structures in Discourse, Interaction, and Cognition. New Jersey: Lawrence Erlbaum Associates. in http://www.discourses.org/OldBooks/Teun\%20A\%20van\%20Dijk\%20\%20Macrostru cture\%20(1980).pdf. 


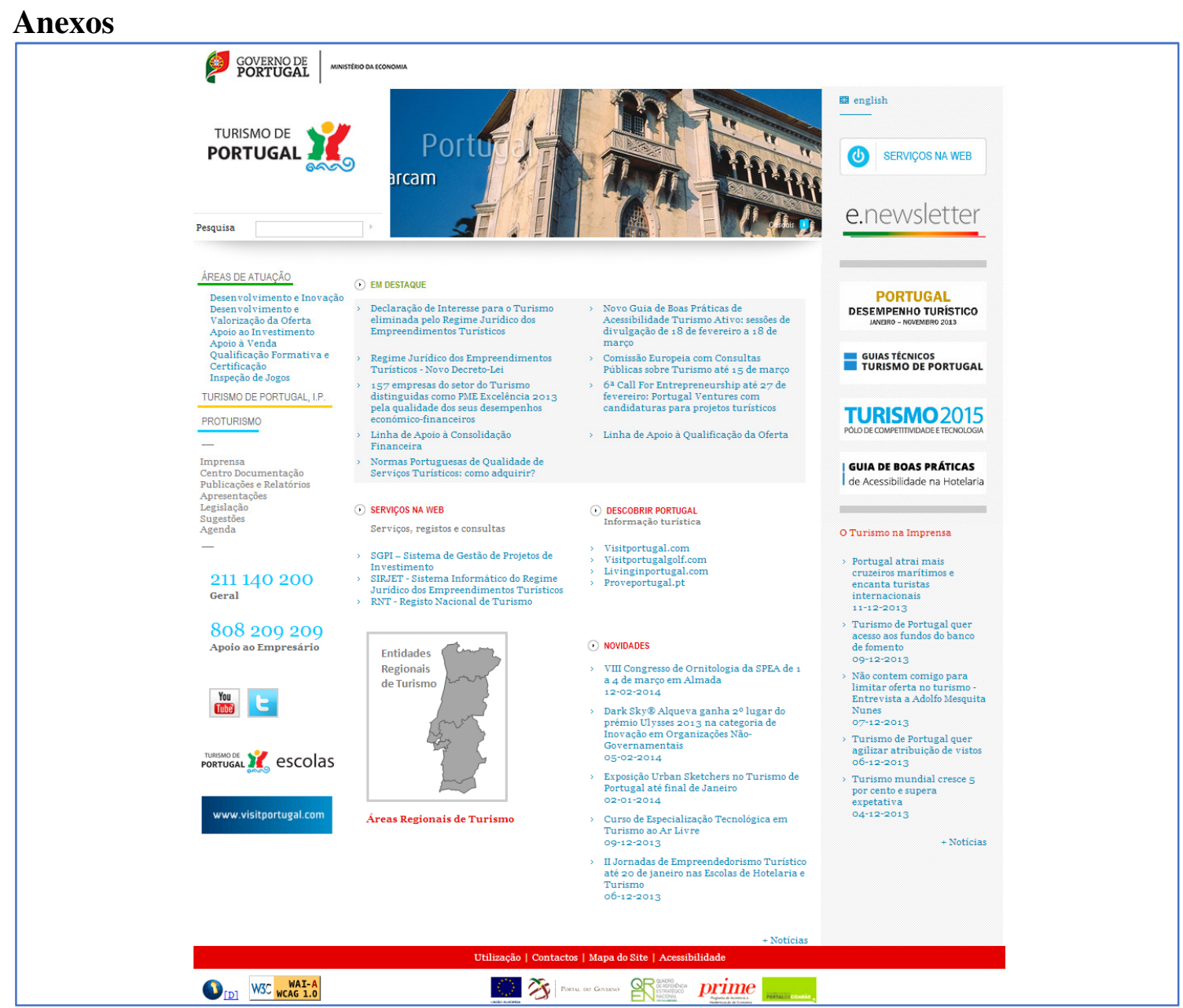

Página inicial - Turismo de Portugal (www.turismoportugal.com) (consultado a 20 de janeiro de 2014) 


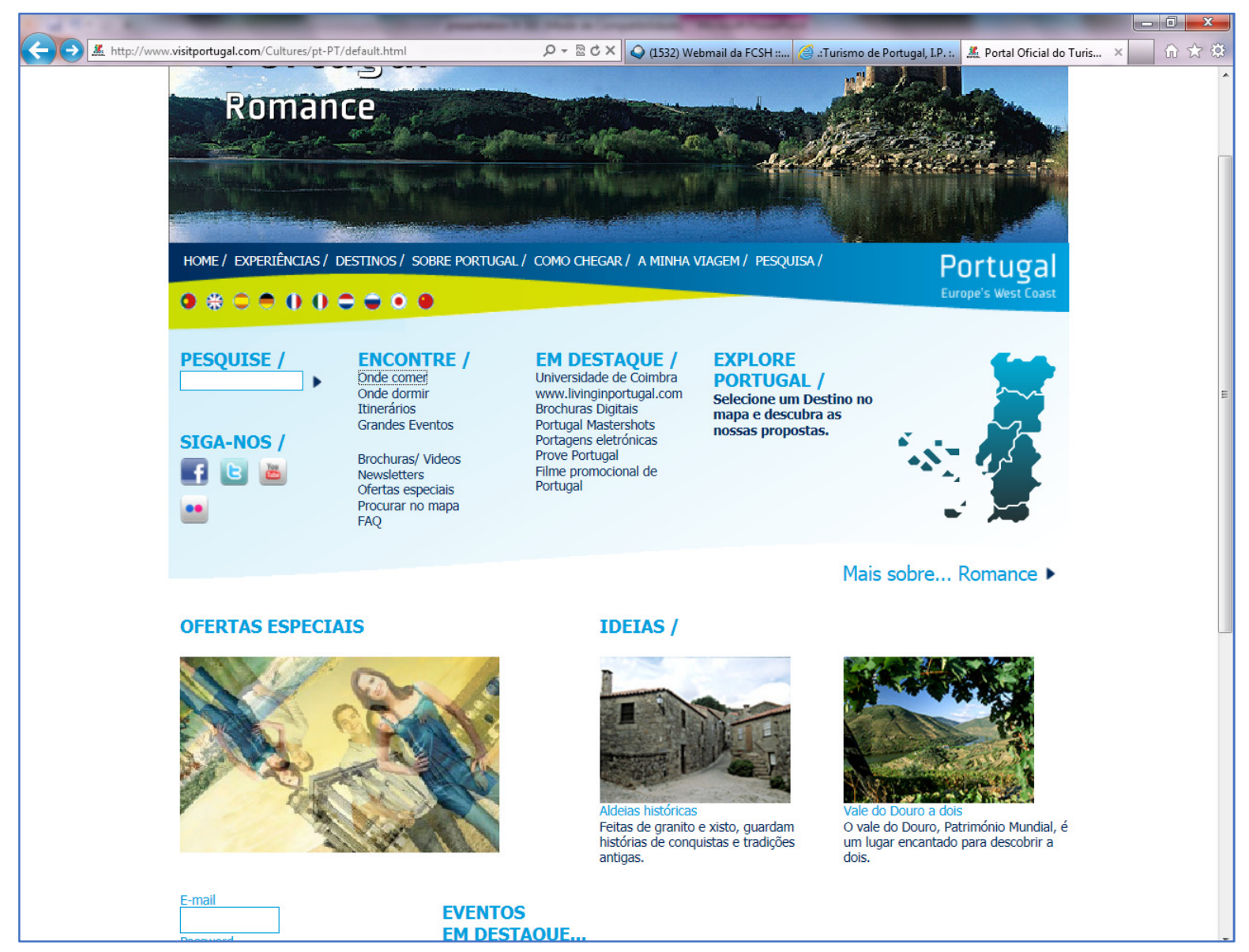

Página inicial - www.visitportugal.pt, consultado a 12 de julho de 2013 


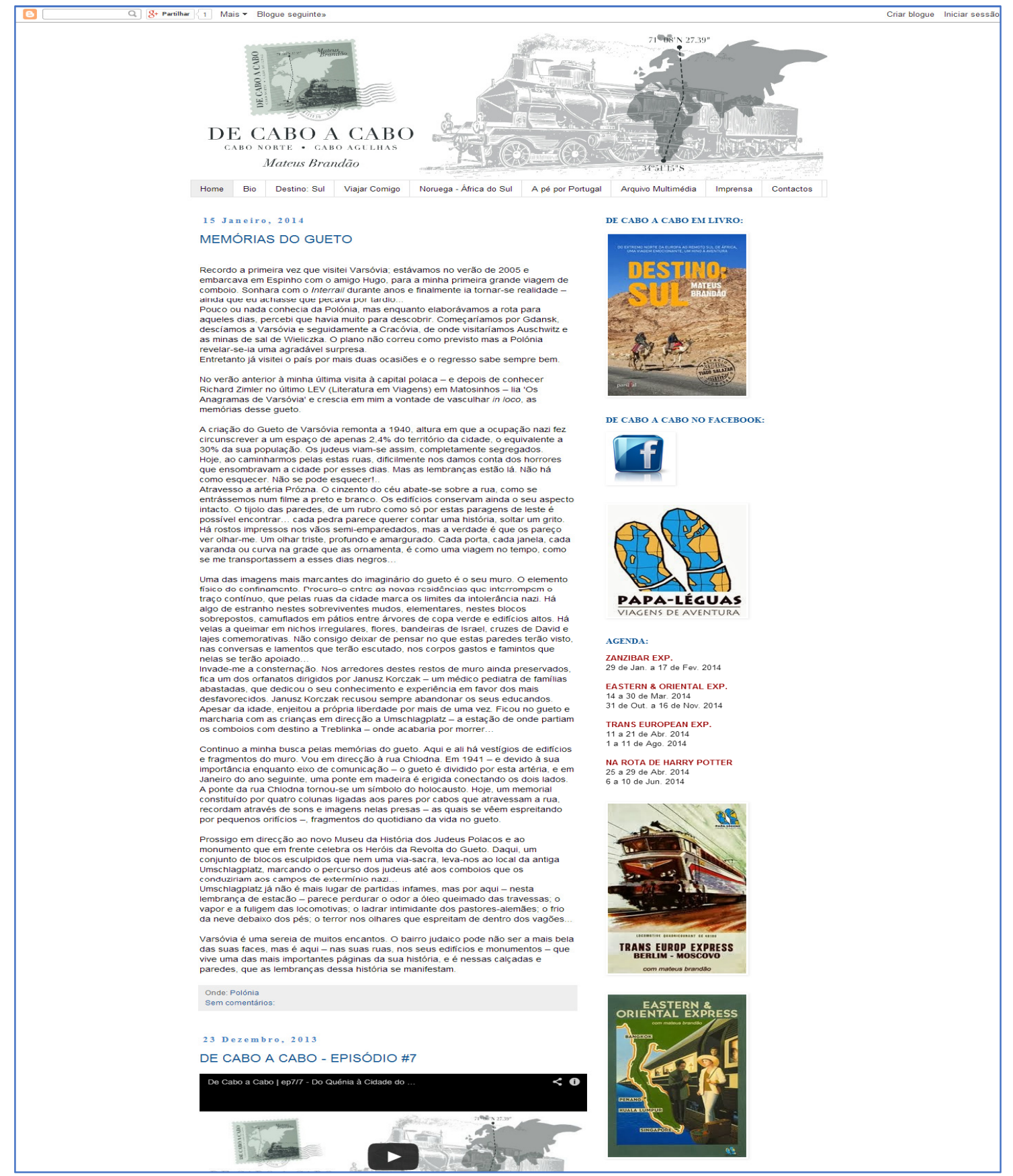

Blog - «Memórias do Gueto », 15 de janeiro de 2014 Cabo a cabo (www.caboacabo.blogspot.com) (consultado a 20 de janeiro de 2014) 